find enough natural history, and many readers may be disappointed by the absence of any application of island theory to pseudo-islands such as nature reserves, but it is a good, clear and constructive book that makes a valuable assessment of the current state of work on island biology.

A.W. DIAMOND

\title{
Domesticated Animals from Earliest Times, by Juliet Clutton-Brock. Heinemann/British Museum (Natural History), £9.95.
}

Good, comprehensive reference books on domesticated animals are few and far between. Zeuner's History of Domesticated Animals, published in 1963, has long been difficult to obtain and most others deal only with the more obvious species, or are superficial. Dr Clutton-Brock's book almost fills the gap-almost, because a few species are not covered. Animals is restricted to mammals, and a few of the newer domesticated species (such as gerbils) are omitted, as are zoo-bred species such as macaques and some of the 'tamed' animals (such as duikers). Nevertheless the breadth of the coverage is impressive. A lucid text is illustrated with excellent line drawings and colour photographs, although some of the 'wild' species look as if they were captive! The reproduction of the black and white photographs is not always of a particularly high standard.

Domestication, probably because of its economic importance, is often a controversial subject. Dr Clutton-Brock asks why 'one species of animal is favoured as a supplier of meat to one nation, whilst to another it is considered a taboo animal, unclean and untouchable?'. Why should pigs be abhorred in some areas, but primary sources of meat in others? The origins of many domestic animals are also controversial, and not every taxonomist will agree with her views, but she presents a concise summary of many controversial areas - such as the origins of the domestic cat.

Domestication is of considerable importance to conservationists since throughout history (and prehistory) there has been a tendency to exterminate the wild ancestors or relatives of domesticated species - a process which continues today.

JOHN A. BURTON

\section{Behavioural Ecology: an evolutionary approach, edited by J.R. Krebs and N.B. Davies. Blackwell Scientific Publications, 18.00 hardback, $£ 8.50$ paperback.}

This is not just a collection of assorted essays, but a carefully integrated book. The offerings of the fourteen authors have a pleasing uniformity in style and level of presentation. The editors themselves have provided a very clear and competent opening chapter, introducing the ideas that permeate the rest of the book; that natural selection is concerned with gene survival, and that the optimal behaviour for the gene-bearing individuals to maximise their inclusive fitness will depend on the behaviour of other individuals and on the ecological circumstances.

The other 12 chapters are grouped into three sections, each introduced by a short but lucid editorial, reflecting the three main problems and animal encounters in its endeavours to maximise the survival of its genes. Predators and Prey considers in four chapters how and where the animal decides to feed, and on what food; whether foraging in a group is advantageous; the particular problems of insect sociality; how the animal avoids being eaten itself. Sex, Mating and Signals consists of five chapters covering the advantages of sexual reproduction; the mate to be selected; how such a mate is found; co-operative breeding; how and why animals communicate. Strategies in Time and Space devotes two chapters to considering how the animal deploys its behavioural options in space, taking up territory or selecting particular habitats, and two to 
investigating deployment in time. One does not wholly escape the trendy titles and jargon phrases that bestrew the sociobiological field; for instance, consider PMP, which is the Pontryagin Maximum Principle ( $M r$ P being a Soviet rocket engineer). But on the whole the contributions are readable without too much irritation.

Throughout emphasis is laid on the theoretical development of quantitative predictions which can be tested, and are tested, by observation and experiment both in field and laboratory. Sometimes, as in much science, there is a flavour of proving the obvious. Sometimes one has the feeling of reading a modern Aesop's fable. But in general we feel the refreshing current of uncommitted thought that is throwing much light on the fascinating problems of how and why animals behave.

G.V.T. MATTHEWS

\section{Malayan Forest Primates, edited by David Chivers. Plenum Press, $\$ 42.50$.}

This is a remarkable book. It summarises 10 years' work on the siamang and lar gibbons, as well as studies of dusky and banded leaf monkeys, and long-tailed macaques, their competitors, and their forest in the Krau Reserve of Malaysia. The style is academic, written for other primatologists, with quantitative analysis where possible - primatology has come of age. It takes a study of this precision and magnitude to deal with a rainforest whose emergent trees tower to 80 metres, and where a primate may have access to 400 species of large tree (over $50 \mathrm{~cm}$ girth at breast height) without counting the hundreds more smaller trees and epiphytes. A gibbon's generation time is nearly a decade, so it also takes a study of this length to show patterns of group change.

Much of the data has been published before. The synthesis has not. Readers interested in cross-species or cross-forest comparison will turn to this volume for information, as will those who want quantitative background to efforts for forest primate conservation. One could cite many different articles - Curtin's deciphering of the unorthodox leaf-monkeys, the MacKinnons' direct comparison of different species at the same place and time, Fleagle's elegant analysis of locomotion. Perhaps the aspect which pleased me most was that Chivers and Raemakers, in their two summary articles dealt with both individuals and statistics. Where they have enough information for mathematical analysis, as in the interrelations of climate, tree phenology, and primate ranging, they have written straight ecology. Where individual lives are important, we are told that too. It is a healthy sign for primatology that both approaches have their place, and that his book of quantitative primate ecology is dedicated to the memory of the siamang, Murgatroyd, 'paragon of monogamous fidelity and fatherhood'.

ALISON JOLLY

\section{Ibexes in an African Environment, by B. Nievergelt. Springer-Verlag, $\$ 40.50$.}

This unusual monograph is centred on the biology of the walia ibex but also deals in detail with the biology of the partially sympatric gelada baboon and klipspringer. In addition there are thumbnail descriptions of the niches within the Ethiopian Simien Mountain ecosystem occupied by a further fourteen mammals, including man. Combined with the description of the vegetation at different altitudes, the work provides the reader with a complex picture of the way the mammals play their part in Simien ecology, and shows a depth of analysis not easily attained in studies of rare species such as the walia, whose low numbers and inaccessible habitat makes data gathering difficult. Academic biologists shun potentially important studies of rare species just because of these difficulties, so it is pleasing to see a work which makes an important contribution to the theory and practice of the accurate evaluation of sparse data typical of studies on rare species. The centre piece is an analysis of the preferred 